\title{
AC 2003-1257: CHIP CAMP: A HIGH SCHOOL OUTREACH PROGRAM
}

Elizabeth McCullough, Kansas State University

Gary Goff,

Marilyn Barger, Hillsborough Community College 
Session 3532

\title{
Tech 4's Chip Camp, a Model for Program for High School Teachers
}

\author{
Marilyn Barger, Gary Goff, Elizabeth McCullough \\ Hillsborough Community College
}

\section{Introduction}

For nearly 5 years the Tech 4 Educational Consortium, a unit of the Florida High Tech Corridor Council, has sponsored "Chip Camps" for high school teachers. Over 700 teachers from schools along the Interstate 4 Corridor that runs from Tampa on the west coast through Orlando to Daytona Beach on the east coast have attended the camp. The two-day camp has a basic schedule that allows for variations to fit the local community where it is offered. The intended audience is primarily high school mathematics, science, computer science and technology teachers and curriculum specialists. The overarching goal of the event is to provide the teacher with information about the electronic microchip industry from the background science, the manufacturing or fabrication processes, employee qualifications for technical staff including technicians, operators, engineers, etc., and career opportunities and business forecasts.

Tech 4's Chip Camps continue to be well received by teachers in central Florida. This paper will review the program of a typical Chip Camp, emphasizing the flexible elements to allow for local talent and industry expertise to be included in the agenda and share the results of the teacher survey. Additionally, it will contrast the 2-day teacher format to the one-day Counselor Camp that the Consortium has also developed. Finally, the paper will share the plans for the future of Tech-4 Chip Camp in the current changing economic times.

\section{The Educational Consortium}

The Florida High Tech Corridor Council (FHTCC) is a semi-governmental institution whose mission is to support and foster community environments that are attractive to high technology businesses and industries considering moving to Florida. To support the workforce capacity aspect of this mission, the FHTCC developed the Tech 4 Educational Consortium to focus on workforce development for these high technology industries. This Consortium is made up of representatives from the University of Central Florida and the University of South Florida, community colleges from across the region, Career Connections Initiatives, the state's Welfare to Work program and area high tech companies. This group meets quarterly at various locations across the state. The original "chip camp" and the upcoming "Tech Camps" have been one of the consortium's major projects since its inception.

Tech 4 also works on the development of degrees and programs designed to train local students for jobs in the high tech arena. This includes an Associate of Science degree in Manufacturing Quality Technology at St. Petersburg College; an Associate of Science degree in Manufacturing Technology at Hillsborough Community College; programs focused on the field of Modeling, Simulation \& Training at Daytona Beach Community College; and a two plus two program in Photonics at Valencia Community College. 


\section{Chip Camp Overview}

Chip Camp is a free, one or two-day programs that provide high school and community college educators with hands-on experience in the semiconductor manufacturing environment and real tools for incorporating that new knowledge into the classroom. To date, more than 700 educators have participated in 17 camps, which are listed in Table 1. Initially all Chip Camps were hosted by Cirent Semiconductor (now Agere Systems) at their facility in Orlando. After the first several camps, it became clear to the Consortium that, although Agere could provide a wonderful setting for the camp, the Camp would have to go "on the road" to reach teachers others than those local to the greater Orlando area. Chip Camp was "mobilized" and to date has been made accessible to educators across the region's 21 counties hosted by local business, industries and educational institutions. Through the Mobile Chip Camps, over 200 educators have been able to learn about the semiconductor industry and take this knowledge back to their classrooms.

\begin{tabular}{|c|c|c|}
\hline DATE & LOCATION & ATTENDEES \\
\hline \multicolumn{3}{|c|}{ 2-Day Teacher Chip Camps } \\
\hline November 1998 & Cirent Semiconductor & 60 \\
\hline March 1999 & Cirent Semiconductor & 60 \\
\hline June 1999 & Cirent Semiconductor & Canceled \\
\hline October 1999 & Cirent Semiconductor & 50 \\
\hline December 1999 & Plant City High School (special) & 25 \\
\hline February 2000 & Cirent Semiconductor & 50 \\
\hline November 2000 & Manatee Community College & 63 \\
\hline April 2001 & Daytona Beach Community College & 43 \\
\hline May 2001 & Hillsborough Community College & 47 \\
\hline August 2001 & Intersil & 48 \\
\hline June 2002 & Lakeland Electric Company & 16 \\
\hline October 2002 & Hillsborough Community College & Canceled \\
\hline \multicolumn{3}{|c|}{ 1-Day Counselor Camps } \\
\hline March 1999 & Cirent Semiconductor & 50 \\
\hline June 1999 & Cirent Semiconductor & 55 \\
\hline November 1999 & Cirent Semiconductor & 40 \\
\hline March 200 & Cirent Semiconductor & 50 \\
\hline February 2001 & St. Petersburg College & 30 \\
\hline August 2001 & St. Petersburg College & 40 \\
\hline TOTA & 17 & 729 \\
\hline
\end{tabular}

Table 1. List of Chip Camps an d Attendees

Chip Camp has continuously gotten the highest ratings (average ratings of over 4 on a 5 point scale) from the attendees for all aspects of the program that includes a number of free materials, catered breakfasts and lunches, and a tour of a local high tech facility. The professional manner in which the Camp is presented, as well as the high quality of the presentations and the variety of 
highly qualified instructors is also important components to a successful event.

\section{Chip Camp in Detail}

Chip Camp provides a wealth of information about the semiconductor industry to workshop participants through various presentations, videos, hands-on activities, and tours. Teachers, counselors, and administrators all find topics of interest and relevance at Chip Camp.

A presentation on the historical development of the microchip and an overview of industry trends lays the foundation for the two-day workshop. Participants get their first taste of the science behind microchips by viewing the video, "A Fab Way to Work". This 14-minute video is geared for high school students and provides an overview of microchip fabrication and careers in the industry. Students and teachers find this video engaging because it is presented from the perspective of a teenager who after daydreaming in physics class has somehow found himself in a semiconductor fabrication facility. Each participant receives this video to take home to use as a resource in the classroom.

The Semiconductors I and II presentations provide the detailed physics and chemistry behind the fabrication of semiconductors. Presenters use animated power point presentations and videos such as "Silicon Magic" to simplify difficult topics. The power point presentations are included on the Semiconductor Science Resource CD, which is given to all participants.

Teachers find many practical biological and environmental applications during the presentation on micro-contamination and water quality. This presentation underscores why semiconductor fabrication requires such a clean environment. Participants are even given the opportunity to try on a "bunny suit" and are judged on their gowning technique.

All Chip Camps provide a tour of a high-tech facility, which utilizes semiconductor fabrication processes. Tours may be on-site or off-site depending on the location of Chip Camp. Participants usually will get to view the clean-rooms where the wafer fabrication occurs and the analytical and diagnostic labs where wafer analysis occurs.

Throughout the two days, information is provided on careers in the semiconductor industry by a variety of sources. Local industry representatives provide the current job outlook and salaries, as well as job skills required for various positions. Local school district representatives highlight efforts the school systems are making to help meet the needs of local industries, including hightech industries.

One of the highlights of Chip Camp is the Applied Learning Activities. These activities are handson activities developed to teach students about the various aspects of semiconductor science including physics, chemistry, biology and math. These activities are designed to use the science of semiconductors to teach existing science objectives and to be interdisciplinary. Most activities integrate both science and math and the Teacher Page includes methods for modifying activities for various ages and course levels. For example, the "Is it Logical?" activity integrates geometry and physics by exploring logic statements and circuit design. In "Doping by Diffusion", students 
use controlled experimentation to test how several variables affect the rate of diffusion of a gas into a silicon wafer. This activity also reinforces the chemistry and math concepts of percentages by calculating the percent diffusion of a gas into the wafer. By trying several of these hands-on activities during Chip Camp, participants gain a better understanding of the science behind semiconductor fabrication. Participants also receive some of the lab supplies necessary to perform these activities with their classes. All of the lab handouts and Teacher Pages are included on the Semiconductor Science Resource CD and can be easily modified for personal use.

\section{Teacher Feedback}

A short evaluation survey is given at the end of every Chip Camp. The surveys responses are always very positive and are summarized in the tables below. The first part of the survey is shown in Table 2 and uses a scale of 1 to 5 ( $1=$ poor, $2=$ fair, $3=$ average, $4=$ good, $5=$ excellent). The results of the second half of the survey are found in Table 3 . These are also based on a 5-point scale ( $1=$ strongly disagree, $2=$ disagree, $3=$ not applicable, $4=$ agree, $5=$ strongly agree). The first column lists the various presentations or activities of the camp. The data presented in the table are the results of one Camp with 46 attendees. The results of the others camps are similar, always averaging over 4.5 on the two different 5-point scales.

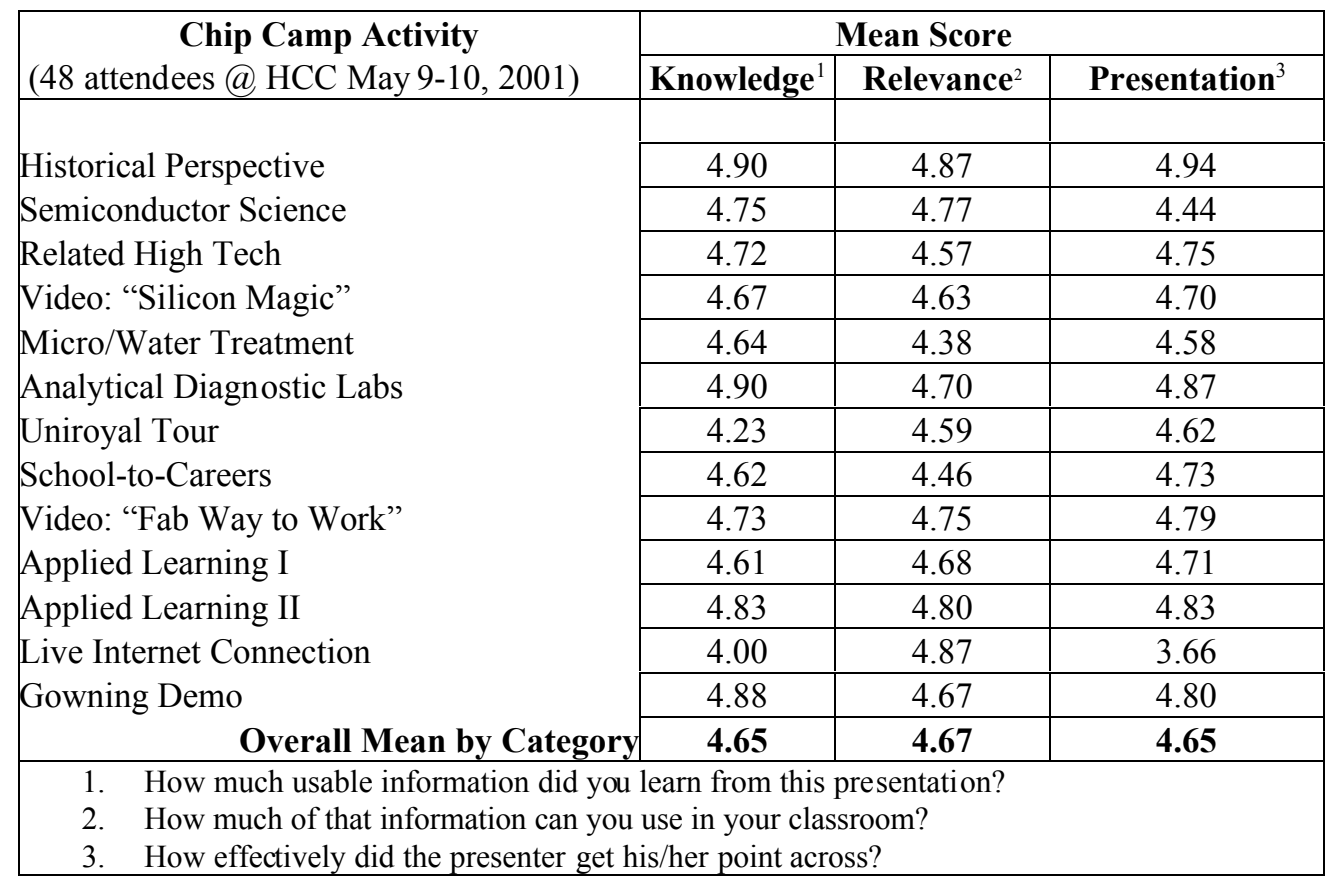

Table 2. First Part of Chip C amp Evaluation Survey 


\begin{tabular}{|l|c|}
\hline \multicolumn{1}{|c|}{ Statement } & Mean Score \\
\hline Content presented at appropriate level & 4.80 \\
\hline Handout/resources material helpful & 4.92 \\
\hline Seminar format appropriate & 4.88 \\
\hline Seminar informative & 4.60 \\
\hline Presenters effective communicators & 4.92 \\
\hline
\end{tabular}

Table 3. Second Part of Chip Camp Evaluation Survey

In addition to this evaluation that was given at the end of every Chip Camp, a follow up survey was mailed to approximately 400 attendees of various chip camps in March 2002. In addition to identification and demographic information there were several questions that requested written comments on how to make the camp better, how to attract more teachers, how the materials were used and what impediments they encountered. The responses to the remaining questions in this survey are summarized in Table 4. Eighty-five responses were submitted

\begin{tabular}{|l|l|}
\hline \multicolumn{1}{|c|}{ Question } & \multicolumn{1}{c|}{ Response } \\
\hline $\begin{array}{l}\text { Have you been able to incorporate any of the } \\
\text { "Chip Camp materials into your curriculum? }\end{array}$ & $75 \%=$ Yes \\
\hline Number of students impacted & Total = 1685 \\
\hline $\begin{array}{l}\text { How useful was the camp in being able to } \\
\text { promote high tech careers to your students? }\end{array}$ & $\begin{array}{l}41 \%=\text { Useful } \\
38 \%=\text { Somewhat useful }\end{array}$ \\
\hline $\begin{array}{l}\text { How useful was the camp in providing you } \\
\text { with information about high tech careers? }\end{array}$ & $\begin{array}{l}69 \%=\text { Useful } \\
20 \%=\text { Somewhat useful }\end{array}$ \\
\hline $\begin{array}{l}\text { How did the Chip Camp program compare to } \\
\text { other training programs? }\end{array}$ & $\begin{array}{l}\text { Well organized, professionally } \\
\text { done, etc }\end{array}$ \\
\hline
\end{tabular}

Table 4. Follow up Survey of 400 Random Chip Camp Participants

Some of the written response comments in this surveys and in the one given directly at the end of each camp overwhelming applaud the Chip Camp as a valuable experience both for the teachers' own professional development as well as a very good resource for topical classroom activities and information. Many of the respondents were using some of the materials in their classrooms. Additionally, strong interest in future Tech Camps on different high technology topics was indicated in these survey responses.

\section{Recruitment}

Various recruitment strategies have been used to attract teachers and counselors to Chip Camps. The leadership of the Educational Consortium and the Florida High Tech Corridor Council regularly meets with the leadership of the school districts and community college and Chip Camps has traditionally been one of the topics. The objective is to get endorsement by the administration in order to facilitate recruitment of attendees throughout the region. This is an important, and successful approach, especially in the current educational environment where teachers have limited opportunities to enroll in professional development activities during the academic year. and moreover, most do not like to leave their classes with a substitute if at all possible. 
The second phase of planning a Chip Camp is to identify an industry, college or school that would like to host the event. Industries and community colleges are the most frequent host institutions as can be seen in Table 1. Once identified, the host organization, the Educational Consortium and the local school district in which the host organization resides meet to decide a date that will work for all parties as well as other logistics of putting on a Chip Camp. At this point, the more traditional marketing begins with the publication of both a paper and electronic brochure application being sent to curriculum specialists, department heads and individual teacher (if possible) in the local schools. This mailing occurs approximately two months prior to the scheduled event. Follow-up to the curriculum specialists and department heads is crucial two to three weeks after the initial mailing of brochures and flyers.

After one Chip Camp, the attendees were surveyed to find out how they found out about the event. Of 46 attendees, over $25 \%$ got the information from their department head and $20 \%$ from their school district administration. Thirty percent reported that they got their information from either the flyers or the registration brochure. The remaining attendees heard about the Chip Camp from their school administration, word of mouth, or some other way.

\section{Costs}

The average cost of the Chip Camps that have been offered thus far is approximately $\$ 5000$. Occasionally, additional costs have included lodging and meals for instructors (generally no more than 4 persons staying over either one or two nights) and a bus to take camp attendees to the tour facility (approximately $\$ 400$ for a half day). Additionally, the Florida High Tech Corridor Council paid for teacher substitutes if the county school district requested help covering these costs. Substitute teacher pay in the central Florida counties averages $\$ 75.00$ per day per teacher. Finally, the startup cost for raw materials for supplies for the Hands-On Learning Activities is approximately $\$ 700$. Table 2 contains some average costs for the various cost items incurred for Chip Camp based on a camp of approximately 50 attendees and 10 speakers/instructors. In the case of Tech 4's Chip Camp, no one camp ever incurred all the costs listed in Table 5.

\begin{tabular}{|l|l|r|}
\hline \multicolumn{1}{|c|}{ Cost Item } & \multicolumn{1}{|c|}{ Details } & \multicolumn{1}{c|}{ Total } \\
\hline Chip Camp food and meals & $\begin{array}{l}\text { (Breakfast, lunch, snacks for 2 days for } \\
50 \text { persons }\end{array}$ & $\$ 3102.49$ \\
\hline Hands-on activities materials & Disposable materials per camp & $\$ 55$. \\
\hline Van rental & supplies to Tampa \& gas & $\$ 1750.00$ \\
\hline Attendee portfolio bags \& goodies & $\begin{array}{l}\text { bag, brochures, video, binder } \\
(\$ 35.00 / \text { teacher x 50) }\end{array}$ & $\$ \mathbf{\$ 5 0 5 4 . 0 1}$ \\
\hline & TOTAL & $\$ 630$. \\
\hline Optional or Occasional Expenses & & $\$ 750$. \\
\hline Hands-on activities materials & Start up costs \\
\hline Bus for facility tour & Per half day & $\$ 3750.00$ \\
\hline Lodgings/meals for instructors & $\begin{array}{l}\text { \$100+\$50 food/night/person plus (avg } \\
5 \text { day-persons) }\end{array}$ & $\mathbf{\$ 5 5 3 0 . 0 0}$ \\
\hline Teacher sub pay & \$75.00/day/teacher x 50 teachers & \\
\hline & TOTAL OCCASIONAL COSTS & \\
\hline
\end{tabular}




\section{The Future: Tech Path and Tech Camps}

The success of Chip Camp has inspired the founders to expand their offerings to additional topics besides microelectronics technology, which is one of the Corridor's focused technology areas. Currently, the Educational Consortium is laying the groundwork to develop similar camps for each of the other five focused industry sectors of the Florida High Tech Corridor Council whose industries have volunteered to help provide input for the new teacher camps. These defined industry sectors are: aviation and aerospace, medical technologies, modeling, simulation and training, information technology, and optics and photonics. The Educational Consortium has evolved to a new name, and is now known as Tech Path. Tech Path has scheduled some of these "Tech Camps" to debut in 2003.

\section{Biographies:}

MARILYN BARGER received her B.S. degree in Chemistry from Agnes Scott College and B.S. and Ph.D. in Civil and Environmental Engineering from the University of South Florida, Tamp Florida. Dr. Barger has over 15 years teaching in Engineering and Technology related programs throughout the country. She is a registered professional engineer in the state of Florida and has been an active member of ASEE for over 10 years. She is currently an associate professor at Hillsborough Community College, Tampa Florida and a Research Associate at the University of South Florida.

ELIZABETH MCCULLOUGH has a B.S. degree in Biochemistry and Chemistry from Hood College; Frederick, MD and a M.S. in Biochemistry from the University of Maryland. She has twelve years of experience teaching in a variety of educational levels and settings including high school, community college, private college and public university level. Currently, Ms. McCullough is a chemistry professor at Hillsborough Community College, Tampa, FL.

MR. GARY GOFF is the Dean of Business and Technologies at Hillsborough Community College (Tampa, Florida). Dean Goff is responsible for the development, management, and execution of all Associate of Science Degrees and technical education and training programs offered at HCC's Brandon Campus. Dean Goff also is active in the articulation and transfer of AS degree and technical programs from secondary through post-secondary institutions.

Proceedings for the 2003 American Society for Engineering Education Annual Conference and Exhibition.

Copyright (C) 2003, American Society of Engineering Education 
Appendix 1. Sample Agenda for Chip Camp

\begin{tabular}{|c|c|}
\hline & $\begin{array}{c}\text { CHIP CAMP AGENDA } \\
\text { HILLSBOROUGH COMMUNITY COLLEGE }\end{array}$ \\
\hline & DAY ONE \\
\hline $8: 30 \mathrm{AM}$ & Continental Breakfast \\
\hline 9:00 AM & Host Welcome \\
\hline 9:10 AM & Introduction and Historical Perspective \\
\hline $10: 15 \mathrm{AM}$ & Video: Fab Way to Work \\
\hline $10: 45 \mathrm{AM}$ & BREAK \\
\hline 11:00 AM & Semiconductors \\
\hline 11:30 A.M. & Video: Silicon Magic \\
\hline 12:00 PM & LUNCH \\
\hline $12: 30 \mathrm{PM}$ & Orlando Science Center Demonstration \\
\hline 1:00 PM & Production / Environment / Contamination / Water Treatment \\
\hline 2:00 PM & Analytical and Diagnostic Labs Tours \\
\hline 3:00 PM & BREAK \\
\hline $3: 15 \mathrm{PM}$ & Digital Career Opportunities \\
\hline 3:45 PM & $\begin{array}{l}\text { Gowning / Questions \& Answers / Tomorrow's Agenda } \\
\text { Tour of HCC Labs }\end{array}$ \\
\hline 4:30 PM & DEPART \\
\hline & DAY TWO \\
\hline $8: 30 \mathrm{AM}$ & Continental Breakfast \\
\hline 9:00 AM & Welcome and Overview \\
\hline $9: 10 \mathrm{AM}$ & Applied Learning Activities I \& II \\
\hline & Understanding Semiconductors \\
\hline & BREAK \\
\hline & Doping and Diffusion \\
\hline 12:00 PM & LUNCH \\
\hline $12: 30 \mathrm{PM}$ & Workforce Development \\
\hline $1: 10 \quad \mathrm{PM}$ & School-to-Careers \\
\hline $1: 45 \mathrm{PM}$ & Travel to Uniroyal Opto-Electronics (UOE) \\
\hline 2:00 PM & Arrival at UOE \\
\hline 2:15 PM & Related Semiconductor Industry \\
\hline 2:45 PM & Tour of UOE Facility \\
\hline $3: 30 \mathrm{PM}$ & Refreshments \\
\hline 3:45 PM & Certificates and Door Prizes \\
\hline 4:00 PM & DEPART \\
\hline
\end{tabular}

